\title{
Contratação obrigatória do menor: uma proposta de alteração em busca do aperfeiçoamento legislativo
}

Mandatory contracting of the minor: a proposal for amendment in search of legislative improvement

Felipe Cunha Pinto Rabelo ${ }^{1}$

\section{Resumo}

Com o avanço social e tecnológico, e a crescente necessidade de aprimoramento da mão de obra, o menor passou a figurar no mercado de trabalho brasileiro como aprendiz, com direitos e deveres expressos em norma específica, inserida principalmente no texto da Consolidação das Leis Trabalhistas (CLT), com determinações para formação técnico-profissional capaz de Ihe assegurar habilidades para uma qualificação precoce e desejável no ambiente laboral. Todavia, com a exigência legal para contratação de uma cota de profissionais aprendizes, e sem a desejável intervenção Estatal na formação destes profissionais, os empresários muitas vezes se vêm compelidos a contrata-los, em contrassenso ao poder diretivo, mesmo sem que haja demanda ou oportunidade em suas empresas para tanto, inclusive em ambientes que não são permitidos a prática laboral a este tipo de profissional. Tais nuances serão abordadas neste trabalho, que culminará em uma proposta legislativa para uma melhor adequação deste tipo de contratação aos ambientes laborais das empresas.

Palavras-chave: Aprendiz. Contabilização da cota. Menor. Atividade incompatível.

Artigo recebido em 31 de Outubro de 2018 e aprovado em 18 de Fevereiro de 2019.

${ }^{1}$ Advogado. Mestrando em Direito Empresarial pela Faculdade Milton Campos; Pós-graduado em Consultoria Jurídico Empresarial pelo Centro Universitário UNISEB; Pós-Graduado em Direito Público pelo Instituto de Educação Continuada da Pontifícia Universidade Católica de Minas Gerais (PUC/MINAS); Graduado pela Universidade da Fundação Mineira de Educação e Cultura (FUMEC). Brasil. E-mail: felipe.rabelo@abdallasa.com.br. 


\section{Abstract}

With the social and technological advancement, and the increasing need for labor improvement, the minor came to appear in the labor market as an apprentice, with rights and duties expressed in a specific norm, inserted mainly in the text of the Consolidation of Labor Laws (CLT ), with determinations for technical-professional training capable of assuring skills for an early and desirable qualification in the work environment. However, with the legal requirement to hire a quota of apprentices, and without the desirable State intervention in the training of these professionals, companies often find themselves compelled to hire them, in contrassense to the directive power, even without any demand or opportunity in their companies for them, including the environments that are not salutary to this type of professional. Such nuances will be approached in this work, which will culminate in a legislative proposal for a better adaptation of this type of contracting to the work environments of companies.

Key-words: Apprentice. Quota accounting. Minor. Iincompatible activity.

\section{Introdução}

No cenário evolutivo das relações humanas, o direito moderno, não só o pátrio como também o estrangeiro, sofre constantes modificações advindas da evolução das relações e suas nuances.

Na relação entre particulares, mais precisamente na relação entre empregado e empregador, as mudanças são ainda mais constantes, vivenciadas, ao longo dos anos principalmente por fatores históricos e econômicos.

No Brasil pós abolicionismo, assim como no restante do mundo, o mercado de trabalho sofreu sensível mudança principalmente em razão das transformações pós primeira Guerra Mundial e criação da OIT em 1919, oportunidade em que as normas trabalhistas passaram a ter mais relevância na relação laboral, em meio a um cenário 
com ampla oferta de mão de obra, mas sem um respaldo legislativo que trouxesse, em sua plenitude, um acobertamento das relações sociais do trabalho.

Havia, no Brasil, leis esparsas mas sem aplicação geral, ocasião em que iniciaram-se os movimentos sociais, em busca de melhores condições de trabalho, evidenciados principalmente entre 1930 e 1945 no governo do então presidente Getúlio Vargas.

Nesta época, o marco principal foi a edição da Consolidação das Leis do Trabalho (CLT) em 1943, com a normatização e conglomeração de regras inerentes à relação empregatícia, sendo a referência legislativa do tema até a presente data, não obstante a importante e ainda vigente inclusão Constitucional, em 1988, dos direitos sociais e garantias fundamentais. Com estas normatizações o direito social passa a ser previsto em sua completude, principalmente nas relações de trabalho.

Além destas mudanças, outra que passou a ser significativa nas relações de trabalho se correlaciona com o avanço tecnológico moderno, marcado principalmente pelo inicio da era da informática na década de 1970, com o surgimento dos microcomputadores.

As atividades laborativas cotidianas ficaram e estão, desde então, cada vez mais ágeis, fruto de uma redução quantitativa dos trabalhos manuais, havendo automatização de processos e procedimentos, e cada vez menos oportunidades no mercado de trabalho, fazendo com que algumas profissões sejam afetadas diretamente por esta automação.

Neste contexto estão os jovens estudantes e profissionais, aqueles que muitas vezes sequer atingiram a maioridade civil, mas que já se veem pressionados a ingressar neste mercado de trabalho em mudança.

Para assegurar a estes indivíduos formas de ingresso no mercado de trabalho competitivo e em constante evolução, o legislador brasileiro previu premissas, direitos e deveres inerentes a eles e aos seus empregadores. 
Tais normas são de extrema relevância para a regularização do oficio ao menor, tornando segura a relação de emprego e ungindo de legalidade os atos que serão praticados por empregado e empregador.

Contudo, além dos direitos e deveres inerentes a esta relação, a legislação brasileira prevê a contratação compulsória de profissional com idade entre 14 e 24 anos, o aprendiz, devendo a empresa reservar cotas em seu quadro funcional para estes profissionais.

O tema central deste trabalho é discutir o problema evidenciado pelo caráter compulsório desta contratação em confronto aos deveres estatais com estes cidadãos, função social da empresa, a liberalidade de contratação por parte do empregador privado daqueles que melhor atenderem aos anseios de sua empresa, com pleno exercício do seu poder diretivo e potestativo na relação empregatícia, e principalmente a contabilização, para efeitos da cota prevista em lei, de trabalhadores que laborem em ambientes os quais as atividades do menor não poderiam ser exercidos, justificando-se esta pesquisa com base em dados do mercado de trabalho atual, utilizando-se de metodologia empírica e dogmática.

Será abordado, precipuamente, um breve histórico sobre o trabalho do aprendiz, com posterior abordagem sobre a evolução legislativa no Brasil, a realidade do mercado de trabalho com a inclusão deste profissional e o problema que a cota, no formato exigido em lei, causa não só aos empregadores como aos empregados, face ao confronto entre a atividade precípua da empresa e o exercício da aprendizagem profissional em todos os estabelecimentos empresários, impactando, por fim, na quantidade de oportunidades disponíveis aos mesmos nas empresas.

\section{Breve histórico sobre o trabalho do menor}

Historicamente, analisando as relações de trabalho, a figura do menor aprendiz não encontrava o respaldo normativo atual, sendo que crianças e adolescentes eram 
muitas vezes submetidos ao labor destinado a adultos, sem nenhuma distinção ou mesmo preservação de sua condição física.

Juristas como ZANGRANDO (2008, p. 1.288) apontam que mesmo de forma precária e muitas vezes ineficaz, desde o código de Hamurabi já havia normas regulando o ensino de ofícios aos menores, sendo certo que nos regimes escravocratas os menores eram utilizados nos trabalhos domésticos desde o momento em que atingiam condições físicas suficientes para tal.

Naquela época, segundo previsão do código de Hamurabi, acaso o artesão conseguisse passar o ofício a seu aprendiz, era ele autorizado a uma adoção legal do mesmo. Se o oficio não fosse repassado ao menor, este poderia retornar à sua casa (WESTERMANN, 1914, p. 304).

O trabalho era extenuante, o que foi majorado sensivelmente na revolução industrial, ocasião em que o ambiente laboral era desfavorável ao labor de forma sã, ocorrendo prejuízos à saúde física e emocional de todos, sejam eles homens, mulheres ou crianças.

\begin{abstract}
A partir da Revolução Industrial e da constante modificação dos padrões de produção até então conhecido por força da introdução da maquina a vapor, homens, mulheres e crianças passaram a ser expostos a doenças ocupacionais e acidentes do trabalho de variadas proporções, provocando o afastamento do trabalhador de suas atividades, bem como acarretando mutilações e mortes, ressaltandose como fatores motivadores as jornadas excessivas de trabalho e a ausência de condições mínimas de segurança, adequadas à execução de qualquer trabalho. (FRANCISCO FILHO e MAZZUILI, 2016, p. 153)
\end{abstract}

Nesta época, os menores, equiparados funcionalmente às mulheres, trabalhavam mais de 12 horas diárias, representando um baixo custo na produção por se tratar de mão de obra barata com maior retorno financeiro e operacional ao sistema produtivo empresarial, o que viabilizava o negócio e o tornava mais competitivo. 
Vivia-se em um período o qual o indivíduo era livre para negociar a sua própria força produtiva, com a intervenção mínima do Estado. A mão de obra disponível era cada vez mais crescente e o número de oportunidades no mercado de trabalho era menor, tornando os salários cada vez mais aviltantes, oportunidade em que o lucro era o ditador das regras da relação empregatícia.

A população crescia em larga escala, sendo que dos nichos mais pobres da sociedade emanavam pequenos trabalhadores, muitos deles sem aptidões físicas e psicológicas para o exercício de uma função industrial, mas que se lançavam ao mercado de trabalho de forma cada vez mais precoce com o intuito de auxiliar sua família no sustento de suas necessidades cotidianas.

Sobre esta época, leciona Martins (2002, p. 555):

A preocupação com o trabalho do menor vem da época das Corporações de Ofício, em que sua assistência era feita para preparação profissional e moral, para conferir-lhe aprendizagem.

Com a Revolução Industrial (século XVIII), o menor ficou completamente desprotegido, passando a trabalhar de 12 a 16 horas diárias. Equiparavam-se os menores às mulheres. Utilizava-se muito do trabalho do menor, inclusive em minas de subsolo.

Após a primeira grande guerra mundial, a utilização e controle sobre a mão de obra do menor passa a ser convencionada pela Organização Internacional do Trabalho (OIT), que iniciou a sua estruturação para proteção do trabalho do menor com a Convenção no 05 de 1919, ratificada pelo Brasil em 1934 (decreto no 423), e que previa, em seu art. 2ㅇ, a impossibilidade do trabalho do menor de 14 (quatorze) anos na indústria, nos seguintes termos:

ARTIGO 2: Não podem as crianças de menos de quatorze anos serem empregadas ou trabalhar nos estabelecimentos industriais, públicos ou privados, ou nas suas dependências, com excepção daqueles nos quais só são empregados os membros de uma mesma família.

Em continuidade a este processo de normatização do trabalho do menor, outras leis surgiram com o passar dos anos, não sendo objetivo deste trabalho destrinchar uma a uma as mesmas, mas cabe importante ressalva ao surgimento da 
Declaração Universal dos Direitos das Crianças no ano de 1959, a qual prevê, em seu art. 9ㅇ, a proteção da criança a quaisquer forma de exploração, determinando não ser permitido que a mesma seja empregada antes da "idade mínima conveniente", sendoIhe assegurada a não ocupação em emprego que "Ihe prejudique a saúde ou a educação ou que interfira em seu desenvolvimento físico, mental ou moral".

Posteriormente, na Convenção no 138 de 1973, a OIT, visando a adoção de critério único quanto a idade do menor, estabeleceu-se, no item 3 do art. 2으, que a idade mínima para admissão em emprego, nos países signatários, não poderia ser "inferior à idade em que cessa a obrigação escolar, ou em todo caso, a quinze anos." Quanto a esta convenção, o Brasil também a ratificou através do decreto $\mathrm{n}$ ㅇ 4.134/2012, ressalvando que "a idade mínima para admissão a emprego ou trabalho é de dezesseis anos."

A CLT trouxe em seu texto normas de proteção ao trabalho do menor e uma forma de contrata-los com objetivo principal de formação profissional, originando a aprendizagem no país. A Constituição Federal brasileira proibiu, desde a sua promulgação em 1988, a diferença de salários, de exercício de funções e de critério de admissão por motivo de idade (art. 70, XXX), com vedação do trabalho noturno, periculoso ou insalubre ao menor de 18 anos e qualquer trabalho ao menor de 16 anos, salvo na condição de aprendiz, aos 14 anos (art. 7으, XXXIII)

Não obstante a inserção constitucional sobre o tema, no Brasil o marco legislativo mais significante se deu com a publicação da lei no 10.097/2000 (que modificou o texto da CLT para, alterando seus dispositivos, prever as condições, requisitos, direitos e deveres do menor aprendiz) e o decreto no 5.598/2005 (que regulamentou a contratação de aprendizes) sendo que suas diretrizes continuam em vigência até os dias atuais. 


\section{Aprendizagem e a legislação brasileira}

Em uma análise do cenário histórico mundial e nacional referente ao trabalho do menor, observa-se que este indivíduo "desde sempre encontrou no trabalho uma modalidade que macula a sua intelectualidade, frustrando e pervertendo a sua efetiva profissionalização, ocorrendo uma precoce castração de sonhos, e tornando-se, em análise última, um adulto sucateado" (TAVALERA, 2006, p. 93)

A aprendizagem então surge como a primeira fase de real desenvolvimento no campo das relações de trabalho para aqueles que ainda flutuam pelo ambiente educacional, sendo a oportunidade do indivíduo, ainda em tenra idade, de se profissionalizar e aprender seu oficio antes mesmo de se consolidar no mercado de trabalho.

O sistema de aprendizagem não é recente e nem uma invenção das instituições modernas, sendo prática antiga, advinda da idade média, quando o mestre artesão acolhia o aprendiz para Ihe fornecer treinamento capaz de realizar o seu ofício, sendo a maioria homens, embora houvesse mulheres em atividades associadas a tapeçaria, bordado e costura (ZANGRANDO, 2008, p. 1302)

No âmbito legislativo brasileiro, o aprendiz encontra definição legal através do art. 428 da CLT, como o jovem com idade entre 14 e 24 anos, "inscrito em programa de aprendizagem formação técnico-profissional metódica, compatível com o seu desenvolvimento físico, moral e psicológico, e o aprendiz, a executar com zelo e diligência as tarefas necessárias a essa formação".

A contratação de aprendizes está regulada no direito brasileiro principalmente nos preceitos inseridos nos arts. 428 a 433 da CLT, havendo previsão expressa no art. 429 sobre a quantidade mínima de aprendizes por empresa (5\% a 15\% dos trabalhadores existentes na empresa, cujas funções demandem formação profissional), e a forma de calcular o numero certo destes profissionais a serem inseridos no ambiente produtivo da empresa: 
Art. 429 da CLT. Os estabelecimentos de qualquer natureza são obrigados a empregar e matricular nos cursos dos Serviços Nacionais de Aprendizagem número de aprendizes equivalente a cinco por cento, no mínimo, e quinze por cento, no máximo, dos trabalhadores existentes em cada estabelecimento, cujas funções demandem formação profissional."

"a) revogada;"

"b) revogada."

"§ $1^{\circ}$-A. O limite fixado neste artigo não se aplica quando o empregador for entidade sem fins lucrativos, que tenha por objetivo a educação profissional."

"§ $1^{\circ}$ As frações de unidade, no cálculo da percentagem de que trata o caput, darão lugar à admissão de um aprendiz."

A CLT, como expresso no caput do art. 429, prevê a obrigatoriedade de contratação de aprendizes por qualquer empresa, sem distinção de sua natureza, mas em postos de trabalho cujas funções possibilitem a sua formação profissional, com exceção da microempresas e empresas de pequeno porte, bem como as entidades sem fins lucrativos que tenham como objeto a educação profissional (art. 14 do decreto $n$ ㅇ 5.598/05).

Como forma de estabelecer parâmetros para cumprimento das determinações expressas na CLT, o legislador editou o decreto $n=5.598 / 2005$, a partir do qual restou expresso, em seu art. 10, para efeitos de computo da cota de aprendizes, a exclusão aquelas profissões que demandem "habilitação profissional de nível técnico ou superior, ou, ainda, as funções que estejam caracterizadas como cargos de direção, de gerência ou de confiança, nos termos do inciso Il e do parágrafo único do art. 62 e do $\S$ $2^{\circ}$ do art. 224 da CLT"

Outro ponto de extrema relevância, e que a lei não previa, se refere àqueles empregadores com poucos funcionários em seu quadro laboral, já que pela sua literalidade, independente do ramo de atividade empresária ou número de funcionários no quadro funcional da empresa, a obrigação de contratar aprendizes era universal. Com a Instrução Normativa SIT no 75 de 2009, mais precisamente em seu art. 2º, a obrigação de contratar aprendizes de acordo com os percentuais previstos na $\mathrm{CLT}$, se limitou àqueles estabelecimentos com 7 (sete) ou mais empregados, o que desobrigou os empregadores de menor porte à contratação destes profissionais.

Sobre o quantitativo de aprendizes e a sua disponibilização física nas empresas, a lei oportuniza aos empregadores a possibilidade de concentrar estes profissionais em 
um de seus estabelecimentos, desde que mantidas as cotas mínimas estabelecidas na norma acima citada.

A lei prevê, ainda, penalização pela não contratação de aprendizes (art. 434 da CLT), o que pode transcender os limites da penalização pura e simples para transmutar-se em uma fiscalização pelos órgãos competentes. Neste ponto, importante ressaltar que o Ministério Público do Trabalho está investido de legitimidade para propor ações na defesa dos interesses coletivos do menor, o que encontra-se expresso no art. 83 da lei complementar no 75/93

Nota-se, portanto, que o aprendiz é uma figura de empregado, protegida pela lei, e que, como tal, participa da força produtiva da empresa, sendo detentor de todos os direitos e deveres inerentes a esta relação, e "figura importante no Direito do Trabalho por traduzir fórmula jurídica de inserção da juventude nos benefícios civilizatórios da qualificação profissional pelo caminho mais bem protegido, que é o da relação de emprego" (DELGADO, 2018, p. 486)

O trabalho do aprendiz, normativamente contemplado até os 24 anos de idade, passou a ser não só legitimado como também pormenorizado quanto à sua aplicação e condições contratuais, inclusive com a obrigatoriedade dos empregadores em reservarem uma cota mínima no seu quadro funcional para estes profissionais.

\begin{abstract}
A lei no 10.097 empresta à aprendizagem uma regulação atualizada, considerando-a, corretamente, uma questão prioritária e merecedora da maior atuação por parte dos empresários e sociedade civil. O desenvolvimento tecnológico do mundo do trabalho, cada vez mais informatizado e robotizado, exige o aprimoramento qualificado dos trabalhadores aptos a intervir no processo produtivo com capacidade crítica, sem polivalentes e multifuncionais (ROMITA, 2002, p. 122)
\end{abstract}

A convivência destes jovens em um ambiente profissional certamente os fará lidar com situações obrigacionais e deveres com os quais só teriam acesso quando atingissem uma maturidade intelectual e social, desenvolvendo aptidões de forma mais precoce, o que os tornando-os capazes de ser mais produtivos no ambiente laboral, evoluindo paulatinamente em suas formações profissionais e acadêmicas. 
Não se discute que o trabalho do menor aprendiz é de extrema relevância social, já que torna cidadãos e profissionais preparados para o mercado de trabalho e convivência social. Contudo, a obrigatoriedade desta contratação pode, de alguma forma, ferir preceitos e direitos do empregador, ou mesmo direitos inerentes ao próprio menor, suprimindo inclusive obrigações que deveriam ser premissas do poder Estatal.

\section{Função social da empresa e o poder diretivo do empregador}

Conforme dito, a legislação brasileira determina a contratação de menores aprendizes por estabelecimentos de qualquer natureza, ressalvadas aqueles com menos de 7 (sete) empregados, devendo ser observada a proporcionalidade variável de $5 \%$ a $15 \%$ dos trabalhadores existentes em cada estabelecimento, cujas funções demandem formação profissional, excluindo-se em tal cômputo, em respeito ao art. 10 do decreto 5.598/2005, aqueles exercentes de cargo de confiança, com formação superior ou técnica.

Neste contexto, o aprendiz se torna empregado da empresa, sendo detentor de direitos e deveres inerentes ao pacto laboral e em consonância com a legislação e com o pactuado individualmente em seus contratos.

O empregado sempre foi encarado como a parte mais frágil da relação de trabalho. Esta desigualdade é tratada explicitamente com a adoção de princípios que auxiliam o empregado quando supostamente poderia haver uma disparidade entre ele e seu empregador. Dentre estes, pode-se citar o princípio da proteção (as normas devem ser exercidas para proteção do trabalhador), princípio da norma mais favorável (na dúvida, aplica-se ao trabalhador a regra que mais o beneficiar), o da irrenunciabilidade de direitos (acaso o trabalhador renuncie a alguns de seus direitos, a renúncia é invalida), o da irredutibilidade salarial (expresso no art. 468 da CLT que determina que a alteração contratual somente pode ser feita com concordância de ambas as partes e desde que não acarrete prejuízos ao trabalhador), entre outros. 
Alguns doutrinadores, justificando a desproporcionalidade entre as partes pactuantes de uma relação de trabalho, defendem a existência do direito tutelar do trabalho, que trata das "regras de proteção ao empregado quanto a sua saúde, ao ambiente e às condições físicas de trabalho, assim como da fiscalização, a ser exercida sobre o empregador, desses mesmos direitos" (MARTINS, 2002, págs. 429 e 430)

A tutela do Estado é importante e, em alguns casos, até essencial para trazer um equilíbrio às partes pactuantes na relação de trabalho. Os exemplos históricos citados são suficientes para demonstrar que a intervenção estatal foi essencial para uma melhora nas condições de trabalho.

Em grande parte do país, as vagas destinadas a menores aprendizes são preenchidas por aqueles oriundos de famílias menos favorecidas, oportunidade em que ingressam no mercado de trabalho não com o intuito principal de aprender e desenvolver suas habilidades laborativas, mas de complementar a renda familiar.

O trabalho do adolescente tem sido amplamente questionado na atualidade, no que tange aos benefícios e prejuízos proporcionados pelo labor. Ao se falar em inserção do menor

no mercado de trabalho, é preciso lembrar que, em geral, trata-se de menores de famílias menos favorecidas.

Assim, conforme Bee (1997, p. 375) apud Fortunatti e Lucas, (2013), alguns adolescentes (menores) trabalham para contribuir com 0 orçamento familiar; outros para adquirir certas coisas que os pais não querem ou não podem proporcionar. Em geral, os pais apoiam seus filhos, referindo-se ao amadurecimento, comprometimento e responsabilidade que essa função pode oferecer (COELHO e ALVES, 2015, p. 36)

Contudo, a lei apresenta algumas distorções, seja quanto à obrigatoriedade de contratação do aprendiz, seja quanto ao cálculo da cota destinada aos mesmos, ou quanto à obrigação do particular e do Estado na formação deste jovem.

Especificamente no caso dos menores aprendizes, a determinação expressa para contratação deste tipo de profissional, independentemente da situação 
econômica, estrutural, histórica, ambiental, laboral ou fiscal da empresa, se analisada com as pujanças da relação trabalhista moderna, fere o poder diretivo do empregador.

Nos dizeres de Nascimento (1996, p. 373):

na relação de emprego a subordinação é um lado, o poder diretivo é o outro lado da moeda, de modo que sendo o empregado um trabalhador subordinado, o empregador tem direitos não sobre a sua pessoa mas sobre o modo como a sua atividade é exercida.

A atividade empresarial é, portanto, caracterizada pelo poder diretivo. Criada a empresa, o empregador é investido, imediatamente, dos poderes que lhe são inerentes para que o empreendimento obtenha o sucesso pretendido. Dessa forma, o empregador organiza, regulamenta e fiscaliza a execução das atividades.

Sobre o poder diretivo e suas peculiaridades na relação de trabalho, leciona Santos (2008, p. 55):

O poder de direção, portanto, pode ser conceituado como as prerrogativas que derivam inclusive da índole constitucional (livre iniciativa) que atribuem ao empregador o direito de livre organização empresarial, desde a ideia inicial de seu empreendimento (projeto de criação) até a consolidação do negócio em todas as suas fases, e na seara trabalhista, o poder de estruturar funcional e hierarquicamente as relações internas entre o trabalho e o capital, inclusive a elaboração do regulamento de empresa

No desenvolvimento de todas essas atividades residem os subsídios para justificar os poderes do empregador: o de criação, o de direção e o disciplinar.

Para Amauri Mascaro Nascimento, poder de direção é "a faculdade atribuída ao empregador de determinar o modo como a atividade do empregado, em decorrência do contrato de trabalho, deve ser exercida. (NASCIMENTO, 1996, p. 374).

$\mathrm{O}$ art. 20 da CLT considera empregador "a empresa, individual ou coletiva, que, assumindo os riscos da atividade econômica, admite, assalaria e dirige a prestação dos serviços"

Empregador, portanto, é aquele que detém o poder diretivo, assumindo os ricos do empreendimento, contratando serviços e pessoas de acordo com suas necessidades e com o perfil desejado para o negócio. 
Com a determinação do art. 429 da CLT há um conflito de lei, pois enquanto há liberalidade do empregador para exercer o seu poder diretivo, assumindo os riscos de sua atividade econômica e, por consequência, contratando os profissionais que entender viáveis para a sua atividade, a mesma lei determina a contratação de aprendizes sem levar em conta tal situação basilar do empregador.

Sem aprofundar no tema função social da empresa, que não é o objetivo central deste trabalho, tem-se que a organização possui responsabilidade e deveres sociais, sendo um deles a geração de empregos com consequente fomentação da economia local.

A empresa, cumprindo com suas atribuições sociais, deve visar não somente o lucro mas também os interesses da sociedade como um todo, cumprindo normas aplicáveis ao seu negócio e propiciando empregos que são capazes de gerar riqueza não só aos diretamente envolvidos e suas famílias como também à comunidade que os circunda.

Não se pode tratar a empresa como uma mera coadjuvante dentro do desenvolvimento pleno de uma sociedade. Através dela, a economia se desenvolve, e, consequentemente, empregos são criados, tributos são devidos ao Estado, que direcionará o valor arrecadado, para a prestação de serviços e utilidades públicas, melhora-se a qualidade de vida e o poder aquisitivo da classe média baixa, fortalece-se a economia e cria-se maior segurança para investimento no país, estabelecendo, dessa forma, desenvolvimento amplo, não se restringindo apenas ao setor empresarial (MENDES, 2012, p. 57)

De fato, a formação de profissionais, ainda antes da maturidade civil, está em conformidade com o exercício da função social da empresa. Contudo, o caráter obrigatório desta contratação por qualquer estabelecimento, salvo as exceções citadas e já legalmente previstas, fere o poder diretivo do empregador e pode atingir diretamente a sociedade que provem desta organização empresarial, já que em razão da obrigação legal de se contratar um aprendiz, a organização pode se ver obrigada a dispensar um de seus empregados acaso não possua recursos financeiros que the 
possibilitem tal contratação, gerando insegurança social e prejuízo à família do desempregado.

De outra ótica, a função social da empresa resta de fato prejudicada, pois o empresário, para conseguir cumprir com suas obrigações financeiras e legalmente estabelecidas, poderá se ver obrigado a dispensar alguns funcionários para abarcar os aprendizes em seu quadro de empregados, atingindo a sociedade.

Nascimento (2013, p. 32), em sua obra sobre o ordenamento jurídico brasileiro, relata:

Não há dúvidas, no entanto, que fatos econômicos influem na legislação trabalhista como acontece com o chamado Direito do Trabalho de crise, assim como fatos políticos também interferem na nossa disciplina como o tipo de Estado (corporativo ou liberal) e, ainda, o Direito do Trabalho reflete-se sobre a vida econômica das empresas, como acontece com o custo do trabalho e a produtividade

Não se deve esquecer que fatores econômicos são essenciais para a continuidade de um negócio, sendo o gasto com funcionários um item de extrema relevância para análise destes fatores.

\section{Cálculo da cota de aprendizes $x$ atividades empresarias que impossibilitam o labor por menor de idade}

Ainda sobre a obrigatoriedade na contratação do aprendiz, deve ser observado que a lei, mais precisamente a CLT, proíbe o trabalho do menor nos casos: a) serviços noturnos (art. 404, CLT); b) locais insalubres, perigosos ou prejudiciais a sua moralidade (art. 405); c) trabalho em ruas, praças e logradouros públicos, salvo mediante prévia autorização do Juiz de Menores, que verificará se o menor é arrimo de família e se a ocupação não prejudicará sua formação moral (art. 405, § 2º).

Contudo, a lei prevê que independente da atividade, as empresas devem contemplar os seus funcionários, com as exceções já mencionadas, no computo do 
cálculo para a cota de aprendizagem, inserindo-se neste cálculo inclusive aqueles que laboram em atividades incompatíveis com o trabalho do menor.

Nova divergência legislativa resta instaura neste ponto, pois se os aprendizes, com idade entre 14 e 18 anos incompletos, não podem realizar atividades nas condições acima citadas, como poderia ser determinada a inclusão daqueles empregados que exerçam na empresa atividades periculosas, insalubres ou noturnas, para o cálculo da cota?

Notório, no nosso sentir, que se não pode o menor trabalhar sob tais condições, os trabalhadores que nesta função se encontram dentro da empresa também não podem ser utilizados para cálculo do percentual referido no art. 429 da CLT.

Apenas como exemplo, como poderia uma empresa de segurança noturna contratar menores aprendizes se contabilizados aqueles empregados que laboram diretamente na sua atividade fim? Fatalmente, por contemplar o maior contingente de empregados em sua atividade principal, estes aprendizes seriam contratados para também fazerem parte do quadro funcional da parte produtiva, laborando em condições que de fato divergem da legalmente estabelecida.

O decreto no 8.740/2016, tentando dirimir tal situação, inseriu o art. 23-A no decreto no 5.598/05 que prevê a possibilidade do empregador, cujas atividades impossibilitem o exercício, por parte do aprendiz, do ensino profissional prático, requerer junto à respectiva unidade descentralizada do Ministério do Trabalho e Previdência Social a assinatura de termo de compromisso para o cumprimento da cota em entidade concedente da experiência prática do aprendiz, sendo a empresa responsabilizada pelos custos do programa de aprendizagem.

Com esta possibilidade, nominada como aprendizagem social, a empresa contrata e remunera o aprendiz, mas ele exerce suas atividades em outro local de trabalho (em uma entidade concedente).

Tal prática é louvável para inserção dos jovens no mercado de trabalho, sendo uma alternativa às empresas que não possuem condições técnicas de abarcar estes 
profissionais no âmbito laboral de suas unidades produtivas, mas, especificamente neste ponto, transfere ao particular uma obrigação do Estado, a de contribuir para a formação destes profissionais.

O risco do empreendimento é do empregador, e os gastos com um profissional não desejável em sua estruturação, ou mesmo no formato de aprendizagem social, pode acarretar prejuízos que inviabilizem a continuidade do negócio.

Não se deve esquecer que ao Estado compete a promoção do bem estar social e igualdade de oportunidades a todos os seus cidadãos, bem como a promoção da inclusão de todos no mercado de trabalho (arts. 3ํ, IV e 203, III da Constituição Federal), partindo, principalmente, da garantia de capacitação a todos os indivíduos para se qualificarem aos cargos disponíveis no atual mercado de trabalho brasileiro.

Nesse sentido, cabe ao Estado, ao promover a dignidade da pessoa humana, garantir a todos os cidadãos a qualificação necessária ao trabalho, bem como cabe ao Estado à promoção da integração de todos os cidadãos ao trabalho, o que se aplica diretamente ao aprendiz.

O texto constitucional de 1988 inaugurou uma mudança paradigmática na doutrina pré-constituição no tocante ao tempo de formação e emprego do menor empregado e do menor aprendiz, denominações usadas na legislação do trabalho. A partir da Constituição de 1988 e do Estatuto da Criança e do Adolescente, as crianças e adolescentes passaram a ser sujeitos de direito, em condição de pessoas e desenvolvimento, e a que se deve assegurar prioridade absoluta na formulação de políticas públicas (MACHADO, 2013, p. 143)

Não se pretende, neste trabalho, exaurir o rol de responsabilidade do empresário e do Estado nas relações de trabalho, mas as possibilidades reais ocorridas no cotidiano laborativo e os confrontos legislativos alhures citados, são suficientes para evidenciar que o processo normativo brasileiro evoluiu consideravelmente sobre a temática envolvendo a normatização do trabalho do aprendiz, mas as nuances que envolvem esta relação empregatícia, e deveres, tanto do Estado quanto da empresa, ainda carecem de maior elucidação por parte do legislador. 


\section{Realidade fática brasileira}

A legislação de fato evoluiu significativamente principalmente o período pós grandes guerras mundiais no Brasil, representando um avanço significativo no campo dos direitos sociais, entre eles aqueles inerentes aos menores trabalhadores. Contudo, a obrigação de contratação de menores aprendizes sem contraprestação ao ente privado, ausência de preparação dos jovens pelo Estado (através de cursos profissionalizantes) ou mesmo o cálculo, na cota de aprendizagem, de funcionários que laboram em condições que não suportam o labor de um menor, reflete diretamente no mercado de trabalho destinado aos aprendizes. As empresas não realizam as contratações no formato legalmente exigido.

Segundo pesquisa realizada pelo IPEA (Instituto de Pesquisas Econômicas), no ano de 2015, dados do IBGE, obtidos através da pesquisa nacional por amostra de domicílios (PNAD) demonstram uma taxa de desemprego de $13 \%$ dos jovens e de $4,4 \%$ para os adultos em 2013. Daqueles que possuem emprego, a mesma pesquisa demonstra que $26,7 \%$ dos jovens e $17,3 \%$ dos adultos ocupados laboram informalmente (IPEA, 2015, p. 4)

Demonstra-se, portanto, que não só o número de jovens desempregados é maior do que o de adultos como também a informalidade profissional daqueles no mercado de trabalho.

Importante ressaltar dados da mesma pesquisa do IPEA sobre os números de contratações de aprendizes.

A pesquisa evidencia que o numero de aprendizes contratados pelas empresas aumentou significativamente ao longo dos últimos anos, como mostra a figura 1 abaixo, mas que apesar deste crescimento, nota-se que o percentual de empresas que contratam em conformidade com a lei, segundo dados de 2013 , é de menos de $1,5 \%$, e que mais de $95 \%$ das empresas brasileiras não possuem aprendizes em seu quadro de funcionário, como demonstra a figura 2 (IPEA, 2015, p. 7). 


\section{Figura 1}

\begin{tabular}{|c|c|c|c|c|c|c|c|c|c|c|c|c|c|c|c|c|}
\hline Idade & $\mathbf{1 9 9 8}$ & $\mathbf{1 9 9 9}$ & $\mathbf{2 0 0 0}$ & $\mathbf{2 0 0 1}$ & $\mathbf{2 0 0 2}$ & $\mathbf{2 0 0 3}$ & $\mathbf{2 0 0 4}$ & $\mathbf{2 0 0 5}$ & $\mathbf{2 0 0 6}$ & $\mathbf{2 0 0 7}$ & $\mathbf{2 0 0 8}$ & $\mathbf{2 0 0 9}$ & $\mathbf{2 0 1 0}$ & $\mathbf{2 0 1 1}$ & $\mathbf{2 0 1 2}$ & $\mathbf{2 0 1 3}$ \\
\hline $\mathbf{1 4}$ & 215 & 82 & 99 & 143 & 582 & 803 & 937 & 1.291 & 1.497 & 2.125 & 2.242 & 2.369 & 2.918 & 4.587 & 5.547 & 6.201 \\
\hline $\mathbf{1 5}$ & 1.063 & 984 & 724 & 1.061 & 2.781 & 5.279 & 7.387 & 8.962 & 11.656 & 13.228 & 16.115 & 16.252 & 20.907 & 27.888 & 35.284 & 37.063 \\
\hline $\mathbf{1 6}$ & 1.616 & 3.145 & 2.917 & 2.684 & 5.747 & 12.365 & 20.341 & 26.060 & 29.776 & 35.100 & 39.100 & 41.787 & 50.723 & 62.558 & 71.509 & 78.111 \\
\hline $\mathbf{1 7}$ & 1.262 & 3.182 & 3.617 & 2.156 & 4.547 & 9.117 & 16.266 & 21.122 & 30.160 & 34.376 & 38.871 & 42.393 & 50.654 & 64.368 & 70.564 & 78.886 \\
\hline $\mathbf{1 8}$ & 70 & 34 & 54 & 76 & 48 & 79 & 121 & 1.392 & 7.052 & 12.972 & 16.317 & 21.968 & 27.846 & 38.406 & 46.573 & 51.847 \\
\hline $\mathbf{1 9}$ & 27 & 1 & 0 & 0 & 0 & 0 & 0 & 246 & 2.521 & 6.687 & 9.565 & 13.145 & 17.758 & 24.289 & 30.454 & 35.355 \\
\hline $\mathbf{2 0}$ & 22 & 0 & 0 & 0 & 0 & 0 & 0 & 125 & 1.396 & 3.560 & 5.804 & 8.250 & 10.464 & 14.043 & 16.927 & 20.387 \\
\hline $\mathbf{2 1}$ & 16 & 0 & 0 & 0 & 0 & 0 & 0 & 72 & 832 & 1.970 & 3.307 & 4.902 & 6.470 & 7.938 & 9.231 & 10.474 \\
\hline $\mathbf{2 2}$ & 4 & 0 & 0 & 0 & 0 & 0 & 0 & 63 & 403 & 1.125 & 1.793 & 2.621 & 3.366 & 4.470 & 4.826 & 5.453 \\
\hline $\mathbf{2 3}$ & 0 & 0 & 0 & 0 & 0 & 0 & 0 & 32 & 193 & 439 & 674 & 1.057 & 1.320 & 1.558 & 1.783 & 1.859 \\
\hline $\mathbf{2 4}$ & 3 & 0 & 0 & 0 & 0 & 0 & 0 & 2 & 6 & 25 & 31 & 51 & 77 & 161 & 141 & 156 \\
\hline $\mathbf{2 5}$ & 2 & 0 & 0 & 0 & 0 & 0 & 0 & 0 & 0 & 0 & 10 & 28 & 35 & 57 & 87 & 113 \\
\hline $\mathbf{2 6}$ & 4 & 0 & 0 & 0 & 0 & 0 & 0 & 0 & 0 & 0 & 9 & 24 & 27 & 42 & 82 & 106 \\
\hline $\mathbf{2 7}$ & 2 & 0 & 0 & 0 & 0 & 0 & 0 & 0 & 0 & 0 & 6 & 30 & 43 & 28 & 90 & 76 \\
\hline $\mathbf{2 8}$ & 1 & 0 & 0 & 0 & 0 & 0 & 0 & 0 & 0 & 1 & 6 & 17 & 25 & 36 & 50 & 85 \\
\hline $\mathbf{2 9}$ & 1 & 0 & 0 & 0 & 0 & 0 & 0 & 0 & 0 & 0 & 9 & 23 & 28 & 30 & 62 & 62 \\
\hline $\mathbf{3 0}$ & 0 & 0 & 0 & 0 & 0 & 0 & 0 & 0 & 0 & 0 & 3 & 18 & 22 & 28 & 65 & 60 \\
\hline Total & 4.308 & 7.428 & 7.411 & 6.120 & 13.705 & 27.643 & 45.052 & 59.367 & 85.492 & 111.608 & 133.862 & 154.935 & 192.683 & 250.487 & 293.275 & 326.294 \\
\hline
\end{tabular}

Fonte: Elaborada pelos autores com base em microdados da RAIS.

Figura 2

\begin{tabular}{|ccccc|}
\hline & Sem aprendizes & $\mathbf{0 \%}-\mathbf{5 \%}$ & $\mathbf{5 \%} \mathbf{- 1 5 \%}$ & $\mathbf{> 1 5 \%}$ \\
\hline 7 - 20 empregados & $98,71 \%$ & $0,08 \%$ & $1,15 \%$ & $0,05 \%$ \\
$21-50$ empregados & $93,85 \%$ & $4,08 \%$ & $1,96 \%$ & $0,11 \%$ \\
$51-100$ empregados & $84,92 \%$ & $11,84 \%$ & $3,05 \%$ & $0,19 \%$ \\
$101-500$ empregados & $75,50 \%$ & $21,43 \%$ & $2,63 \%$ & $0,45 \%$ \\
$501+$ empregados & $74,07 \%$ & $24,52 \%$ & $0,94 \%$ & $0,47 \%$ \\
\hline Média & $\mathbf{9 5 , 6 4 \%}$ & $\mathbf{2 , 7 8} \%$ & $\mathbf{1 , 4 9} \%$ & $\mathbf{0 , 1 0 \%}$ \\
\hline
\end{tabular}

Fonte: Elaborada pelos autores com base em microdados da RAIS

Não se pode confundir o crescimento numérico de contratações de aprendizes com uma real adoção dos termos da lei com consequente entendimento da sociedade civil e do Estado para a importância deste profissional para o mercado de trabalho, pois além de não representarem uma parcela significativa de trabalhadores no mercado de trabalho atual, grande parte este crescimento se deu por terem sido os empresários compelidos a fazê-lo em virtude de aplicação de multas administrativas advindas da fiscalização do trabalho (IPEA, 2015, p. 8)

Importante citar, dentro desta análise, que apesar dos grandes empregadores (aqueles que possuem mais de 1000 funcionários no seu quadro de empregados) 
terem sido responsáveis pela contratação de mais de $25,5 \%$ do total de empregados no ano de 2016, segundo dados do Ministério do Trabalho e Emprego, gerados pela análise da Relação Anual de Informações Sociais da Empresas (RAIS), 30,9\% do total de empregos foi gerado por pequenos e médios empresários, sendo aqueles que possuem entre 5 e 49 funcionários, como se observa da tabela abaixo (BRASIL - MTE, 2016):

Figura 3

\begin{tabular}{|l|c|r|r|r|r|c|c|}
\hline $\begin{array}{l}\text { Tamanha do } \\
\text { estabelecimento: }\end{array}$ & $\mathbf{2 0 1 0}$ & $\mathbf{2 0 1 1}$ & $\mathbf{2 0 1 2}$ & $\mathbf{2 0 1 3}$ & $\mathbf{2 0 1 4}$ & $\mathbf{2 0 1 5}$ & $\mathbf{2 0 1 6}$ \\
\hline Até 4 empregados & 3.669 .698 & 3.839 .970 & 3.972 .862 & 4.120 .510 & 4.248 .410 & 4.276 .595 & 4.230 .672 \\
\hline De 5 a 9 & 3.546 .585 & 3.759 .170 & 3.929 .131 & 4.080 .937 & 4.187 .610 & 4.216 .846 & 4.136 .698 \\
\hline De 10 a 19 & 4.022 .658 & 4.258 .590 & 4.438 .942 & 4.560 .105 & 4.682 .038 & 4.669 .014 & 4.555 .557 \\
\hline De 20 a 49 & 5.177 .935 & 5.516 .317 & 5.671 .544 & 5.847 .950 & 5.952 .585 & 5.796 .572 & 5.545 .038 \\
\hline De 50 a 99 & 3.649 .726 & 3.843 .344 & 3.957 .539 & 4.049 .295 & 4.083 .225 & 3.900 .391 & 3.737 .397 \\
\hline De 100 a 249 & 4.637 .845 & 4.887 .520 & 5.025 .103 & 5.152 .916 & 5.162 .073 & 4.914 .657 & 4.678 .727 \\
\hline De 250 a 499 & 3.854 .345 & 3.945 .094 & 4.072 .663 & 4.169 .982 & 4.180 .050 & 3.959 .246 & 3.741 .288 \\
\hline De 500 a 999 & 3.769 .090 & 3.920 .885 & 3.964 .714 & 4.110 .108 & 4.095 .353 & 3.954 .444 & 3.697 .273 \\
\hline 1000 ou Mais & 11.740 .473 & 12.339 .741 & 12.426 .214 & 12.856 .630 & 12.980 .166 & 12.373 .042 & 11.737 .548 \\
\hline TOTAL & $\mathbf{4 4 . 0 6 8 . 3 5 5}$ & $\mathbf{4 6 . 3 1 0 . 6 3 1}$ & $\mathbf{4 7 . 4 5 8 . 7 1 2}$ & $\mathbf{4 8 . 9 4 8 . 4 3 3}$ & $\mathbf{4 9 . 5 7 1 . 5 1 0}$ & $\mathbf{4 8 . 0 6 0 . 8 0 7}$ & $\mathbf{4 6 . 0 6 0 . 1 9 8}$ \\
\hline
\end{tabular}

Fonte: MTb/RAIS.

Demonstra-se, com base nos dados fáticos do mercado de trabalho brasileiro, que a obrigatoriedade da cota atinge em grande parte o pequeno e médio empresário, que pode ter o seu negócio comprometido na aplicação literal da lei, sem análise das nuances descritas neste trabalho.

Todos os fatores citados neste trabalho, se agrupados, demonstram a necessidade premente de mudança legislativa e de mentalidade empresária e governamental para tratar sobre o tema face a relevância do aprendizado precoce nas relações de trabalho.

\section{Conclusão}

Não se nega a importância do aprendiz no mercado de trabalho, pois a evolução técnica destes profissionais possibilitará, sem dúvidas, um precoce e desejável amadurecimento, que gerará profissionais mais qualificados e que, por 
consequência, oportunizarão maiores resultados à empresa. A empresa deve cumprir seu papel social, sendo responsável não somente pelo lucro a ser gerado ao investidor, como também pela preservação do ambiente social e ambiental, assim como geração de empregos para uma parcela da comunidade em que a mesma está inserida, gerando renda às famílias locais.

Contudo, esta contratação não pode se dar apenas e tão somente pelo caráter obrigatório que a lei prevê, sem distinção das atividades e nuances que revertem a empresa, pois tal fato é um dos fatores que inviabilizam a perpetuidade do negócio e a consequente geração de empregos. Fato crucial, portanto, não é a simples contratação do aprendiz, mas a conscientização da sua importância para o mercado produtivo baseada em mudança legislativa e de postura da sociedade civil e do Estado.

Ao Estado deve ser imputada a responsabilidade constitucional de promover a integração ao mercado de trabalho dos aprendizes, o que não deve se ater apenas a imposição legislativa ao empregador privado, com punições advindas de fiscalizações pelo não cumprimento da cota legal, sendo desejável a sua participação atuante na formação dos aprendizes, capacitando os mesmos para o exercício de atividades profissionais cotidianas.

Uma mudança legislativa para excluir do cálculo da cota de aprendizes (minimamente daqueles que possuem idade entre 14 e 18 anos incompletos), os profissionais que na empresa exerçam atividades incompatíveis com o trabalho dos menores é, no sentir deste autor, medida necessária para que não haja labor destes profissionais em atividades de risco, inclusive trazendo legalidade à prática do trabalho.

Ademais, a simples obrigação ao empresário de contratação destes profissionais, em desacordo com o seu poder diretivo, não nos parece a solução para o problema do desemprego aos jovens no país, devendo o empresário ser incentivado nesta contratação com redução de impostos e outras vantagens fiscais pela formação destes aprendizes para o mercado de trabalho. 
A mudança de mentalidade é algo desejável! O mundo cotidiano está em constante modificação e vivemos em uma era de desafios e desenvolvimento tecnológico, sendo essencial a capacitação de jovens na inserção deste novo mercado de trabalho, o que deve se processar com incentivos aos empresários na contratação de aprendizes, modernização da legislação e atuação do Estado neste contexto.

\section{Referências}

BRASIL, Ministério do Trabalho e emprego. Dados Nacionais 2016. RAIS. relatório anual de informações sociais - Análise dos principais resultados. Disponível em: <http://pdet.mte.gov.br/index.php/rais>. Acesso em 01 de setembro de 2018

COELHO, Marly dos Reis Pereira e ALVES, Ivete Maria de Oliveira. O MENOR APRENDIZ: contrato de aprendizagem e o desenvolvimento social nas relações de trabalho. AMPLIANDO Revista Científica da Facerb, CIDADE, v. 2, n. 1.p. 21-44, Jan./Jun.2015.

DELGADO, Mauricio Godinho. Curso de direito do trabalho. 17ạ ed. São Paulo: LTr, 2018.

FRANCO FILHO, Georgenor de Souza; MAZZUOLI, Valério de Oliveira (Org). Direito internacional do trabalho: o estado da arte sobre a aplicação das convenções internacionais da OIT no Brasil. São Paulo: LTr, 2016.

IPEA. INSTITUTO DE PESQUISA ECONOMICA. A aprendizagem e a inserção de jovens no mercado de trabalho: uma análise com base na RAIS. Brasília, 2015. Disponível em: $<\mathrm{ftp}$ ://ftp.mtps.gov.br/obtrabalho/central-de-conteudos/relatorios/relatorio-aprendizenviado.pdf >. Acesso em 30 de agosto de 2018.

MACHADO, Sidnei. Proteção jurídica do trabalho do jovem no Brasil. 2013. Disponível em:<http://www.ipardes.pr.gov.br/ojs/index.php/revistaparanaense/article/view/552 > Acesso em: 14 de agosto de 2018

MARTINS, Sergio Pinto. Direito do Trabalho - 16a ed., atualizada até maio/2002 - São Paulo : Atlas, 2002 
MENDES, Frederico Ribeiro de Freitas. A concretização da Função Social da Empresa pela sua atividade-fim. In Revista Magister de Direito Empresarial, Concorrencial e do Consumidor. Porto Alegre: Magister, 2012 (out/nov), no 47

NASCIMENTO, Amauri Mascaro. Ordenamento Juridico Trabalhista. São Paulo : LTr, 2013

NASCIMENTO, Amauri Mascaro. Curso de Direito do Trabalho - 12a ed. São Paulo: Saraiva, 1996

ROMITA, Arion Sayão. O novo regime de aprendizagem. Brasília : Revista do TST, vol. $68, \mathrm{n} 01$, jan/mar 2002

SANTOS, Enoque Ribeiro dos. Limites ao poder disciplinar do empregador: a tese do poder disciplinar compartilhado. Revista IOB Trabalhista e Previdenciária. São Paulo: v. 19, n. 223 , p. $52-76$, jan. 2008

TAVALERA, Glauber Moreno. Trabalho do menor. Brasília : Revista do TST, vol. 72, no 1, jan/abril 2006

ZANGRANDO, Carlos Henrique da Silva. Curso de direito do trabalho : tomo III. São Paulo : LTR, 2008

WESTERMANN, W. L. Apprentice Contracts and the Apprentice System in Roman Egypt. Classical philology 9, no. 3 (1914): 295-315

WOOD, Ellen. Modernity, posmodernity or capitalism? Review of Intemational Political Economy, University of Sussex/Brighton, Routledge, v. 4, n. 3, Autumn, 1997. p. $539-560$. 